\title{
Der lange Weg zum Sixpack
}

\section{Erhard Taverna}

Dr. med., Mitglied der Redaktion

Sein Idol ist Arnold Schwarzenegger in der Pose des Mr. Universe, Sieger im Amateur-Bodybuilder-Wettbewerb 1967. Das Studium hat der Sohn des Dorfpfarrers geschmissen, weil er die meiste Zeit im Fitnessstudio oder auf seiner Bude beim Training mit Kugelhanteln und dem Stahl-Springseil verbringt. Der Erfolg lässt sich sehen. Aus dem in der Schule gemobbten Schwächling ist ein Muskelpaket geworden. Was ihn stört ist einzig seine beginnende Gynäkomastie. Noch ist der erhöhte Blutdruck kein Problem. Seit ihm der Vater das Studiengeld kürzt, hat er Mühe, das viele Geld für die teuren Proteinpräparate und die empfohlenen Zusatzprodukte aufzutreiben. Auch Schwarzenegger hat viel später, als er schon Gouver-

Der Erfolg lässt sich sehen. Aus dem in der Schule gemobbten Schwächling ist ein Muskelpaket geworden.

neur von Kalifornien war, zugegeben, während seinen jugendlichen Trainingsjahren Anabolika gebraucht zu haben.

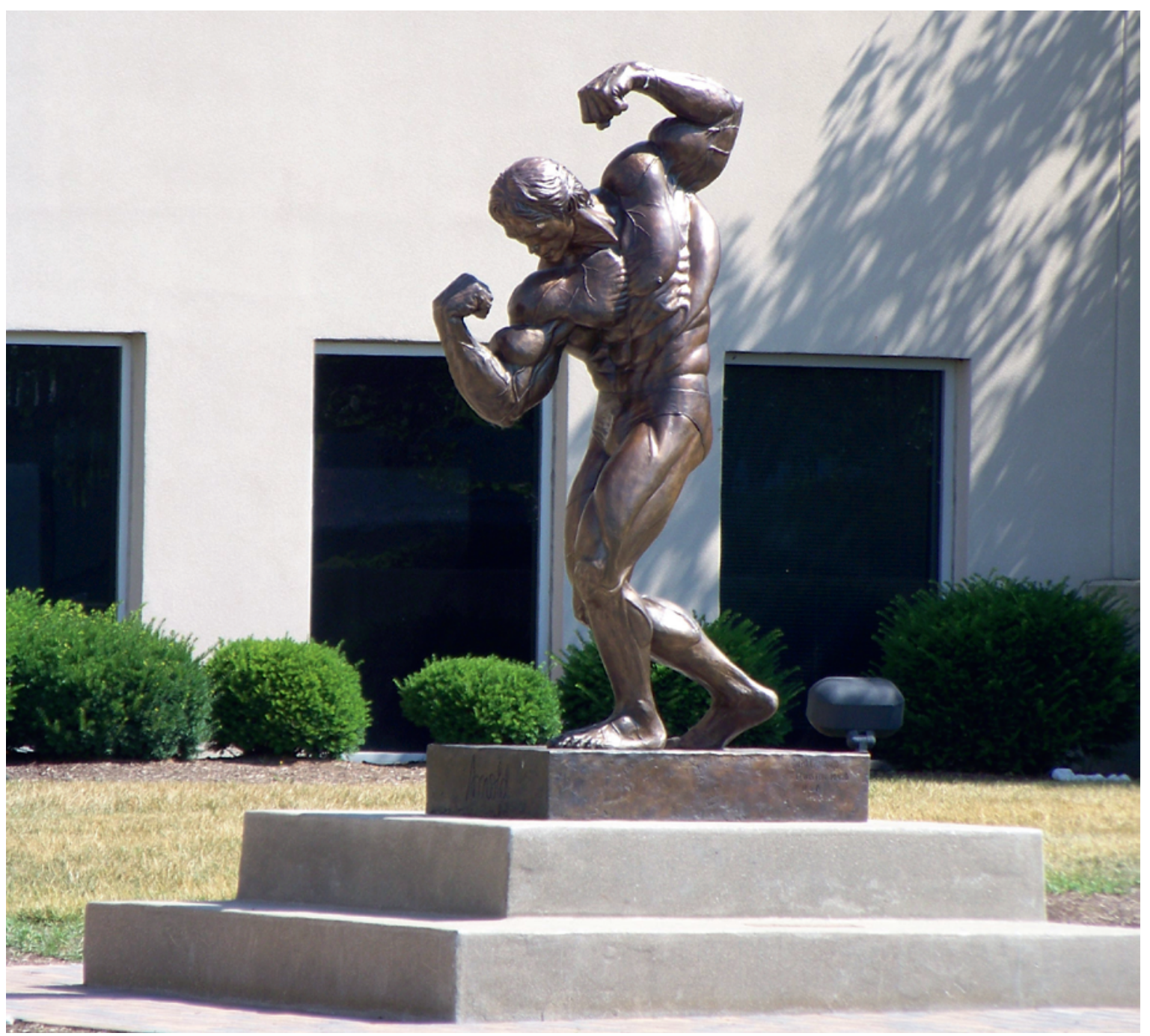

Statue zu Ehren Arnold Schwarzeneggers in Columbus. 
Exzessives Training allein genügt nicht, um im Wettbewerb der Profi-Muskelprotze mitzuhalten. Die Show fordert ihre Opfer. Die meisten Gewinner werden nicht alt. Dabei erhält der Mr. Olympia oder Mr. Universe Gewinner als Trophäe die Figur eines Mannes, der, nur mit Schnurrbart und Feigenblatt bekleidet, in der Hand eine Hantel hält. Dieser Oskar für die preisgekrönten Muskelhelden ist Eugen Sandow, dem Vater des Bodybuildings nachgebildet, der vor genau 150 Jah-

\section{Die Show fordert ihre Opfer. Die meisten Gewinner werden nicht alt.}

ren als Friedrich Wilhelm Müller in Preussen zur Welt kam. Er gründete in London das erste Fitnessstudio der Welt und wurde 1911 von König Georg V. zum Professor für wissenschaftlichen Körperkult ernannt. Der stärkste Mann der Welt machte eine sagenhafte Karriere als siegreicher Ringer, Modell an Kunstakademien, Akrobat und Showman, der sich in Privataudienzen von Damen der viktorianischen Gesellschaft gegen Entgelt betasten liess. Sandows Vorbilder waren die antiken, griechischen Statuen. Er formte seinen Körper nach ihren Massen und Proportionen und demonstrierte ihn bronzebemalt und lichtbestrahlt im abgedunkelten Theater auf der Bühne. Wer seinen perfekten Körper erlangen wollte, konnte seine Newsletters abonnieren, seine Bücher und Artikel lesen und weltweit Studios aufsuchen, die nach seinem

\section{Sandows Vorbilder waren die antiken, griechischen Statuen.}

System lehrten. Ausser Fernkursen per Post vertrieb er sein "gesundes und stärkendes Kakaopulver». Vielen Prominenten wie Theodore Roosevelt oder Conan Doyle diente der europäische Herkules als Muskelcoach. Bereits 1898 organisierte er den ersten Wettbewerb im Show-Bodybuilding in London, damals noch unter Ausschluss der Damen. Sandow starb angesehen, als Millionär und Familienvater 1925, nur 58-jährig, vermutlich an einer Syphiliserkrankung.
In den bizarren Muskelfiguren der heutigen Shows mit Stripeinlagen hätte sich Sandow nicht wieder erkannt. Die Ästhetisierung männlicher Ideale wie Herkules, Samson oder Goliath folgt heute den Comic-Vorbildern, die Film und TV-Serien weiter verbreitet haben. Superhelden, wie Iron Man, Captain America oder «Der unglaubliche Hulk» setzen eigene Standards. Vor allem der grünhäutige Berserker Hulk mit seiner grotesk hypertrophen Muskulatur führt zu immer neuen, tiefschürfenden Interpretationen. Psychologen konstruieren aus der Geschichte des gamma-verstrahlten Kernphysikers Dr. Bruce Banner, der in seinen Wutanfällen zum kindlichen Muskelpaket mutiert, Symptome einer typischen Zeitgeistfigur. Hulk inspiriert seit Jahrzehnten Filmemacher und Playmobil-Hersteller. Die Haudrauf-Spektakel des Grünlings begeistern Klein und Gross. Hulk, was Klotz oder Koloss bedeutet,

\section{Vielen Prominenten wie Theodore Roosevelt oder Conan Doyle diente der europäische Herkules als Muskelcoach.}

ist weder Frauendarling noch antikes Harmonieideal. Der Klotz fasziniert, wie Spiderman oder Batman und ihre ebenso mächtigen Gegenspieler, auch wenn es vom grünen Monstrum inzwischen viele Varianten gibt, die aus ihm sogar einen Professor machen. Eugen Sandow, Erfinder einer neuen Sportart und Leitfigur aller Waschbrettbäuche, war als eingebürgerter Brite ein grosszügiger Mäzen. Ihm zu Ehren wurde in der Antarktis ein Felsen über einem Gletscher zum Mount Sandow.

Etwas Geschichte mit therapeutischer Wirkung. Der Jurastudent hat inzwischen die Anabolika ab- und sein Studium fortgesetzt. Weniger stahlhart als zuvor, dafür selbstsicher und gesund, büffelt er für sein Examen. Auf dem neuen Schwarzenegger-Poster posiert der Österreicher als Terminator. Ein bisschen Adrenalin tut auch einem Stubenhocker gut.

\section{Bildnachweis}

Von Aisupova - Eigenes Werk, CC BY-SA 3.0, https://commons.wikimedia org/w/index.php?curid=20218535 